Case Report

\title{
Prenatal Diagnosis of Cardiac Diverticulum with Pericardial Effusion in the First Trimester of Pregnancy with Resolution after Early Pericardiocentesis
}

\author{
Raquel Garcia Rodriguez, Azahara Rodriguez Guedes, Raquel Garcia Delgado, \\ Lourdes Roldan Gutierrez, Margarita Medina Castellano, and Jose Angel Garcia Hernandez
}

\author{
Prenatal Diagnosis and Fetal Therapy Unit, Department of Obstetrics and Gynecology, University Maternity Hospital of Canaries, \\ Las Palmas, 35004 Gran Canaria, Spain
}

Correspondence should be addressed to Raquel Garcia Rodriguez; raquelgarciarod@gmail.com

Received 19 May 2015; Revised 6 September 2015; Accepted 13 September 2015

Academic Editor: Babatunde A. Gbolade

Copyright (C) 2015 Raquel Garcia Rodriguez et al. This is an open access article distributed under the Creative Commons Attribution License, which permits unrestricted use, distribution, and reproduction in any medium, provided the original work is properly cited.

\begin{abstract}
Cardiac diverticulum is a rare anomaly, which may present in association with pericardial effusion. Only few cases diagnosed during fetal life have been published and only in 12 cases pericardiocentesis was made with good postnatal outcomes in $83 \%$ of the cases. In the first trimester of pregnancy only 6 cases were reported. We described the largest series of cases published. We describe a case of cardiac diverticulum complicated with pericardial effusion during the first trimester of pregnancy and resolved by intrauterine pericardiocentesis at 17 weeks of pregnancy. We made a systematic review of the literature with the cases reported of cardiac diverticulum, management, and outcomes.
\end{abstract}

\section{Introduction}

Cardiac diverticulum is a rare anomaly, which may present in association with pericardial effusion and may produce complications such as pulmonary hypoplasia or hydrops fetalis. Only a few cases diagnosed during fetal life have been published and 10 cases during the first trimester of pregnancy.

We describe a case of cardiac diverticulum complicated with pericardial effusion, which was diagnosed at 14 weeks of pregnancy and resolved by intrauterine pericardiocentesis at 17 weeks of pregnancy.

We review the ultrasound findings, management, and outcomes in 34 cases published in the literature, 21 of which were associated with pericardial effusion, and in 12 cases a pericardiocentesis was performed. In this group of pericardiocentesis, 10 cases have good postnatal outcomes.

In light of the good neonatal outcome of this procedure, we propose that early pericardiocentesis should be considered as a therapeutic option in these cases that do not resolve spontaneously.

\section{Case Report}

A 22-year-old sub-Saharan woman, gravida 2 para 1, was referred to the Unit of Prenatal Diagnosis and Fetal Therapy at $12+4$ weeks of gestation for a fetal hydrothorax. The ultrasonographic study revealed the presence of severe pericardial effusion. The first trimester screening showed $2.9 \mathrm{~mm}$ nuchal translucency, reversed ductus venosus a-wave, absent nasal bone, and absence of tricuspid regurgitation. All other anatomical and echocardiographic findings were normal. Biochemical markers were $\beta$-hCG $0.14 \mathrm{MoM}$ and PAPP-A $0.72 \mathrm{MoM}$. The screening results indicated high risk of chromosomopathy. Therefore, a chorionic villus samplingbiopsy study was performed, which revealed a normal $46 \mathrm{XY}$ karyotype. On week 14 of pregnancy, pericardial effusion was still observable. Furthermore, a two-millimeter anechoic image was found on the heart apex, with a narrow base and expanding from the ventricular wall into the pericardium. Blood flow could be observed through this structure with color Doppler 

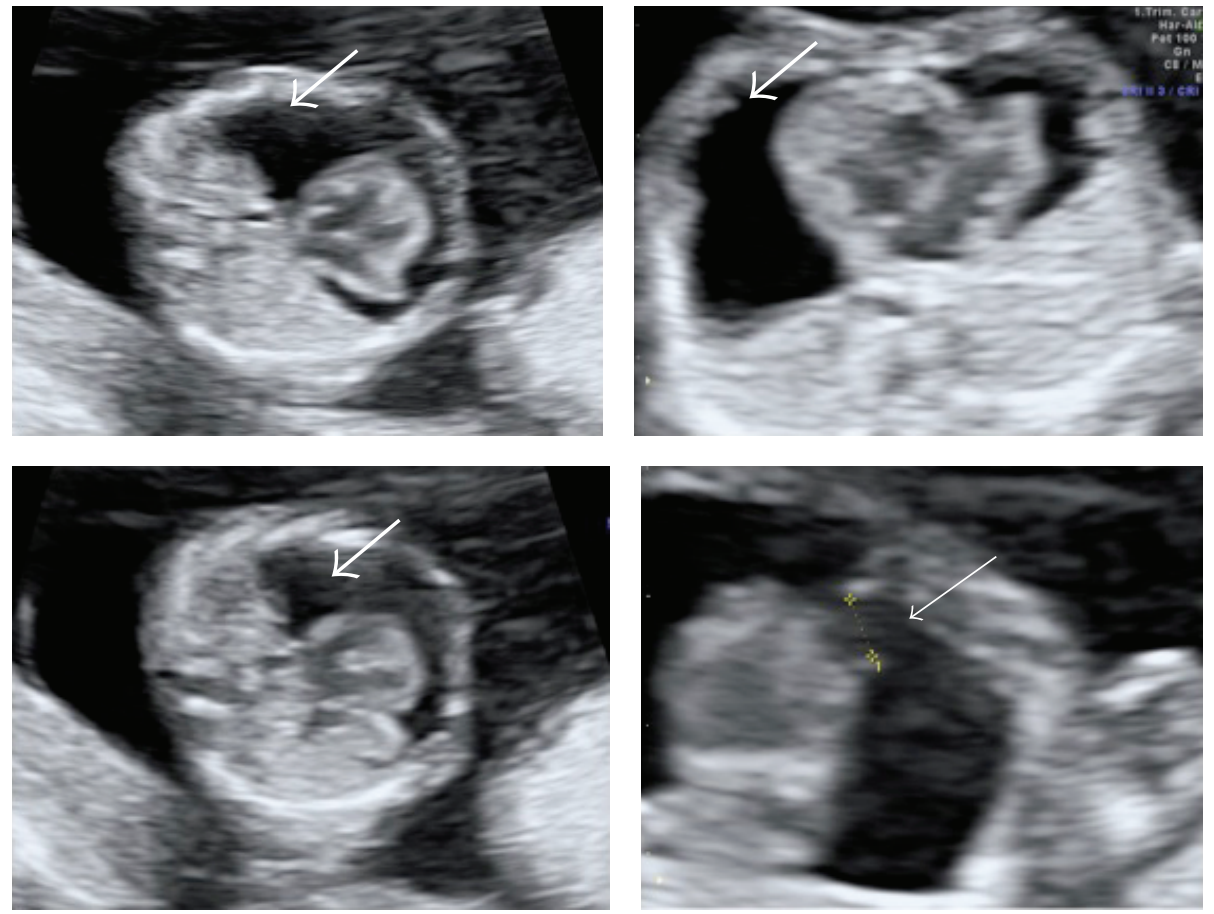

FIgURE 1: Transversal view of the thorax during the 14th week of pregnancy, where severe pericardial effusion (thick arrow) and cardiac diverticulum in the ventricular apex (thin arrow) can be observed.
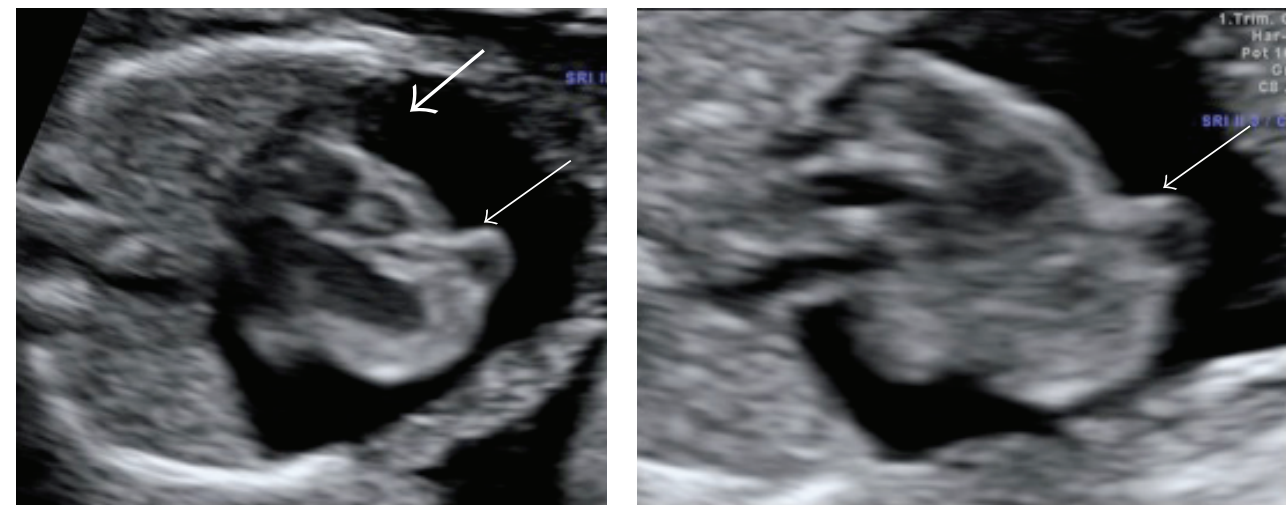

FIGURE 2: Transversal view of the thorax during the 16th week of pregnancy. Severe pericardial effusion (thick arrow) and cardiac diverticulum in the ventricular apex that connects with the ventricle (thin arrow) can be observed.

sonography. On this basis, the diagnosis of a cardiac diverticulum was made (Figure 1). The rest of the echocardiography was normal.

Serial ultrasound studies were conducted until week 17 of pregnancy (Figure 2). Given that the pericardial effusion persisted, pericardiocentesis with a 20-gauge needle (like amniocentesis) was performed and a clear serum-like fluid was removed. After pericardiocentesis, both lungs expanded and only a small amount of residual fluid remained. Results of the infections study of the amniotic fluid (Toxoplasma, cytomegalovirus, rubella, herpes virus, and parvovirus B19) were negative. A week after pericardiocentesis, no new pericardial effusion was detected. The clinical picture remained stable until week 25, when cardiomegaly and thickening of the ventricular walls were observed, thus leading to a diagnosis of hypertrophic myocardiopathy. Ultrasound studies showed normal ventricular function without signs of cardiac failure. On week 40, a boy was born in eutocic delivery, with 3150-gram body weight, 9/10 Apgar score, and 7.29 umbilical artery $\mathrm{pH}$. The newborn was admitted to hospital for cardiological study. Subsequent serial examinations ruled out hypertrophic myocardiopathy, although they showed residual pericardial effusion, an apical cardiac diverticulum, persistent small ductus venosus, and permeable oval foramen. At present, the child is four years old, remains asymptomatic, and is on a prophylactic treatment with acetylsalicylic acid. He is being monitored in annual follow-up visits to the Service of Pediatric Cardiology. 
TABLE 1: Differential diagnosis of the different types of diverticulum and aneurism.

\begin{tabular}{llll}
\hline & Isolated apical diverticulum & Nonapical diverticulum & Aneurism \\
\hline Etiopathogeny & Embryogenesis defect & $\begin{array}{l}\text { Congenital or acquired focal defect in } \\
\text { the muscle wall (viral infection, injury } \\
\text { to coronary artery, etc.) }\end{array}$ & $\begin{array}{l}\text { Congenital or acquired focal defect in } \\
\text { the muscle wall (viral infection, injury } \\
\text { to coronary artery, etc.) }\end{array}$ \\
\hline $\begin{array}{l}\text { Implantation base on } \\
\text { ventriculum }\end{array}$ & Narrow base & Narrow base & Wide base \\
\hline Size & Small & Small & Large \\
\hline $\begin{array}{l}\text { Development during } \\
\text { pregnancy }\end{array}$ & $\begin{array}{l}\text { Constant size throughout } \\
\text { pregnancy }\end{array}$ & Constant size throughout pregnancy & Enlarging with gestational age \\
\hline Histology & $\begin{array}{l}\text { Myocardium in walls; usually } \\
\text { presenting the three layers } \\
\text { (myocardium, pericardium, and } \\
\text { endocardium) }\end{array}$ & $\begin{array}{l}\text { Myocardium in walls, usually } \\
\text { presenting the three layers } \\
\text { (myocardium, pericardium, and } \\
\text { endocardium) }\end{array}$ & $\begin{array}{l}\text { Myocardium disruption, usually } \\
\text { presenting thin myocardium and } \\
\text { fibrous tissue }\end{array}$ \\
\hline Kinesis & Normal & Normal & Akinetic, hypokinetic, and dyskinetic \\
\hline Contractility & $\begin{array}{l}\text { Contractility in synchrony with } \\
\text { heart's rhythm }\end{array}$ & $\begin{array}{l}\text { Contractility in synchrony with heart's } \\
\text { rhythm }\end{array}$ & $\begin{array}{l}\text { Contractility paradoxical with heart's } \\
\text { rhythm }\end{array}$ \\
\hline $\begin{array}{l}\text { Copending on the associated } \\
\text { anomalies }\end{array}$ & $\begin{array}{l}\text { Usually not occurring } \\
\text { Good }\end{array}$ & $\begin{array}{l}\text { Good } \\
\text { failure, and rupture }\end{array}$ \\
\hline
\end{tabular}

\section{Discussion}

A cardiac diverticulum is a protrusion located on the ventricular wall, in close communication with it. This rare entity has been scarcely reported in the literature. Prenatal diagnosis may be difficult when it appears isolated [1]. Since such formations are closely communicated with the heart ventriculum, bidirectional blood flow may be observed through them with color or pulsed Doppler sonography [1].

Two types of diverticula are known: apical and nonapical $[2,3]$; their characteristics are shown in Table 1. Apical diverticulum of the left ventriculum may be of three different types: apical isolated diverticula, which are not associated with other malformations; multiple diverticula, which are located on the diaphragmatic or anterior surface of the ventriculum; and large apical diverticula, which are associated with midline thoracoabdominal malformations or with the Pentalogy of Cantrell [4]. Although their etiology is not known, they seem to be caused by local weakening of the ventricular wall, which may in turn be due to possible embryogenesis defects [5], secondary to infections, or caused by local ischemia resulting from coronary anomalies, such as stenosis, hypoplasia, intimal proliferation, and thrombosis [6-8]. Differential diagnosis should include aneurisms (Table 1) [6, 9-12], myocardiopathy, Ebstein's anomaly, and auriculoventricular regurgitation [9].

We made a systematic review of the literature with PubMed and Embase database search in English, French, or German which was performed without any restriction of publication date or journal, using the following key words: fetal cardiac diverticulum. The last search was updated in December 2012.

For each included case we focused on the following criteria: time of diagnosis, pericardial effusion association, management, intrauterine evolution, associated complications, and time of delivery fetal outcome (intrauterine death/ stillbirth, death after delivery, and survival). We excluded the cases of cardiac aneurysm. After reviewing 27 articles, 34 cases published between 1990 and 2012 met the above criteria in which cases of fetal cardiac diverticulum were presented (Table 2) with our case included.

It was most frequently diagnosed during the second trimester of pregnancy (51\%). During the first trimester, 29\% of cases were diagnosed; three of them presented increased nuchal translucency. This entity affects male fetuses more than female ones $(3: 1)$; its most frequent location is on the right ventriculum (70\%) and the most frequently involved area is the heart apex (57\%). Ultrasonographic findings associated with diverticula include pericardial effusion, cardiomegaly, septal defects and arrhythmia with fetal death before delivery, and hydrops [6, 13, 14]. Pericardial effusion is the most frequently associated finding (63\%) and should be considered an indirect sign of the presence of cardiac diverticula. Although the etiology of effusion is not known, it has been proposed to result from the diverticulum rubbing the pericardial walls or from heart failure. Thus, the observation of pericardial effusion makes it necessary to examine the cardiac function $[1,6,15]$.

A problem associated with pericardial effusion is that the resulting compression may produce heart failure and pulmonary hypoplasia. The management of such cases (Table 3) usually varies from performing pericardiocentesis to adopting an expectant approach. In a published series of 22 cases, pericardiocentesis was performed in $12(56 \%)$ fetuses of 14 to 25 weeks' gestational age, with an outcome of 10 cases that progressed favorably (83\%) and 2 intrauterine deaths (17\%) $[16,17]$. In the cases of fetal death, the pericardial fluid was blood. In the same series, 7 cases were managed with an expectant approach (32\%). Five of them showed spontaneous 


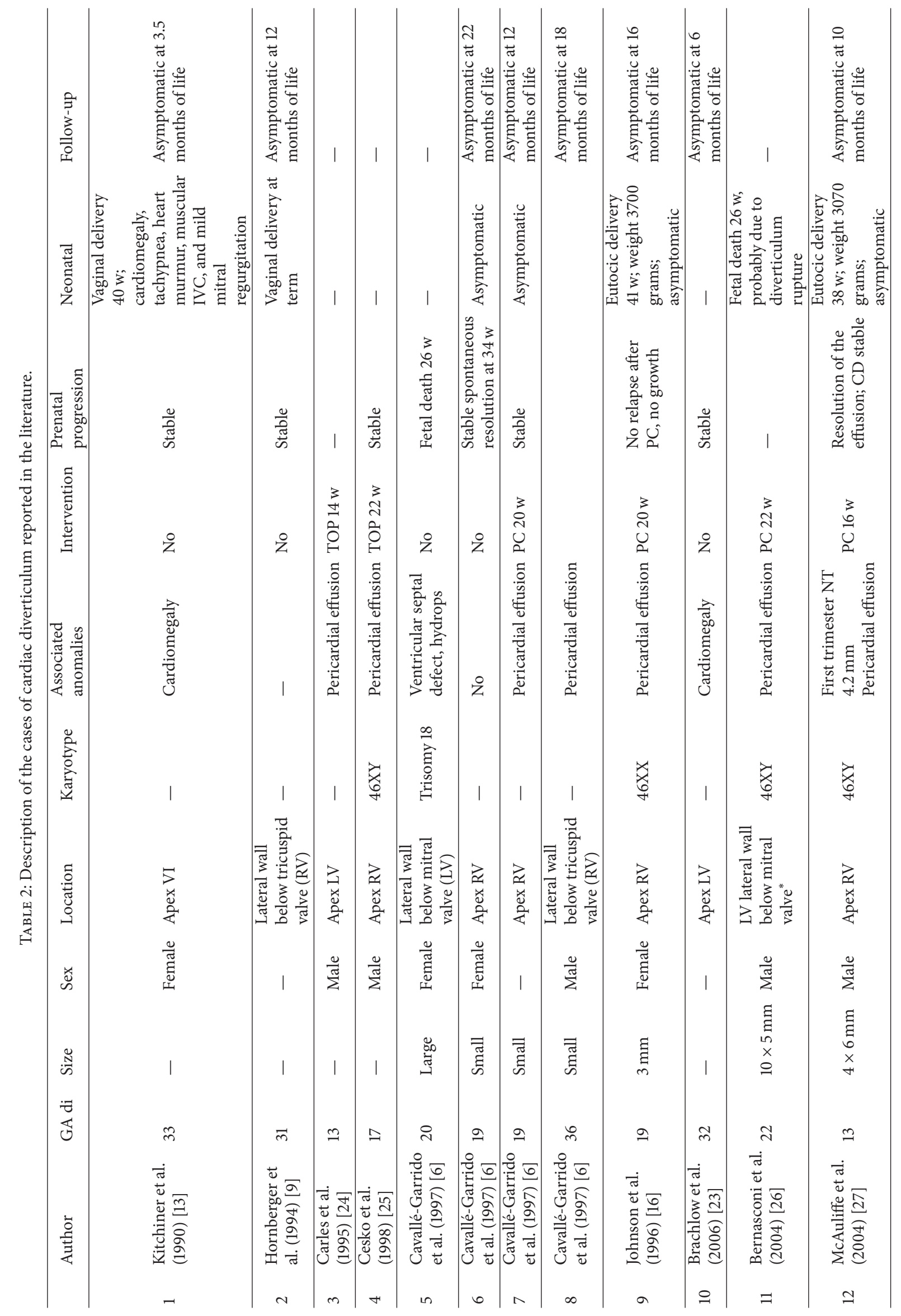




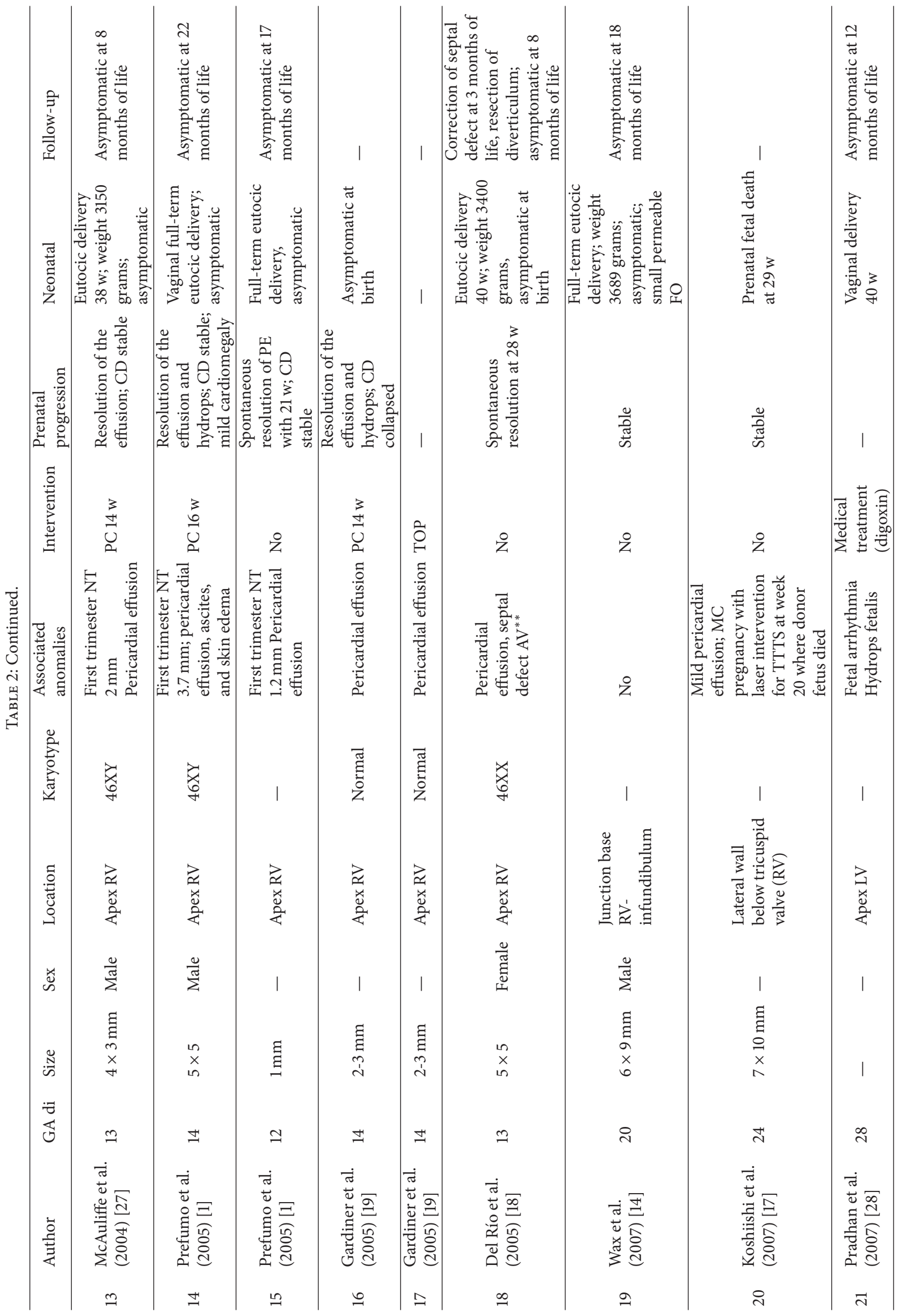




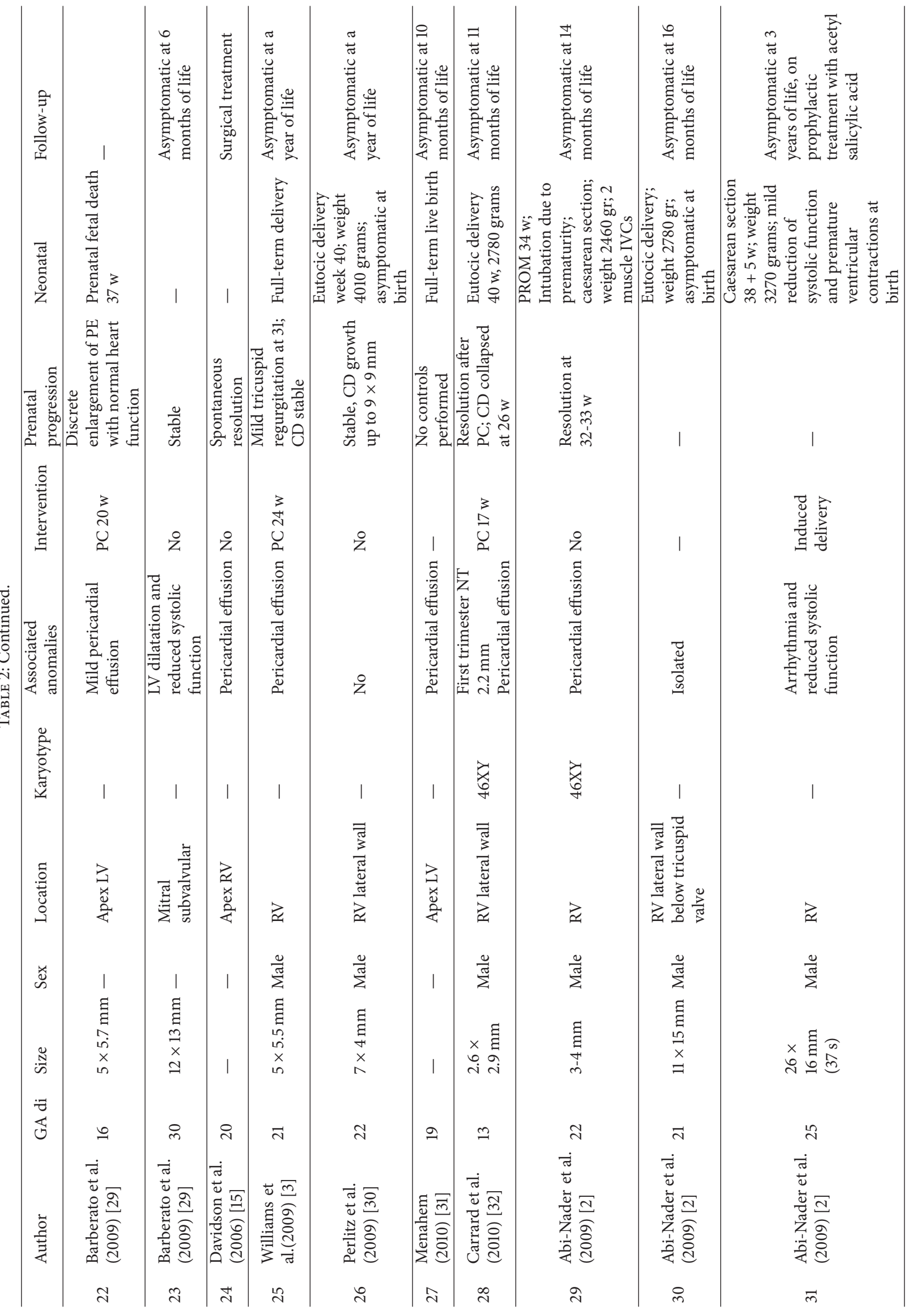




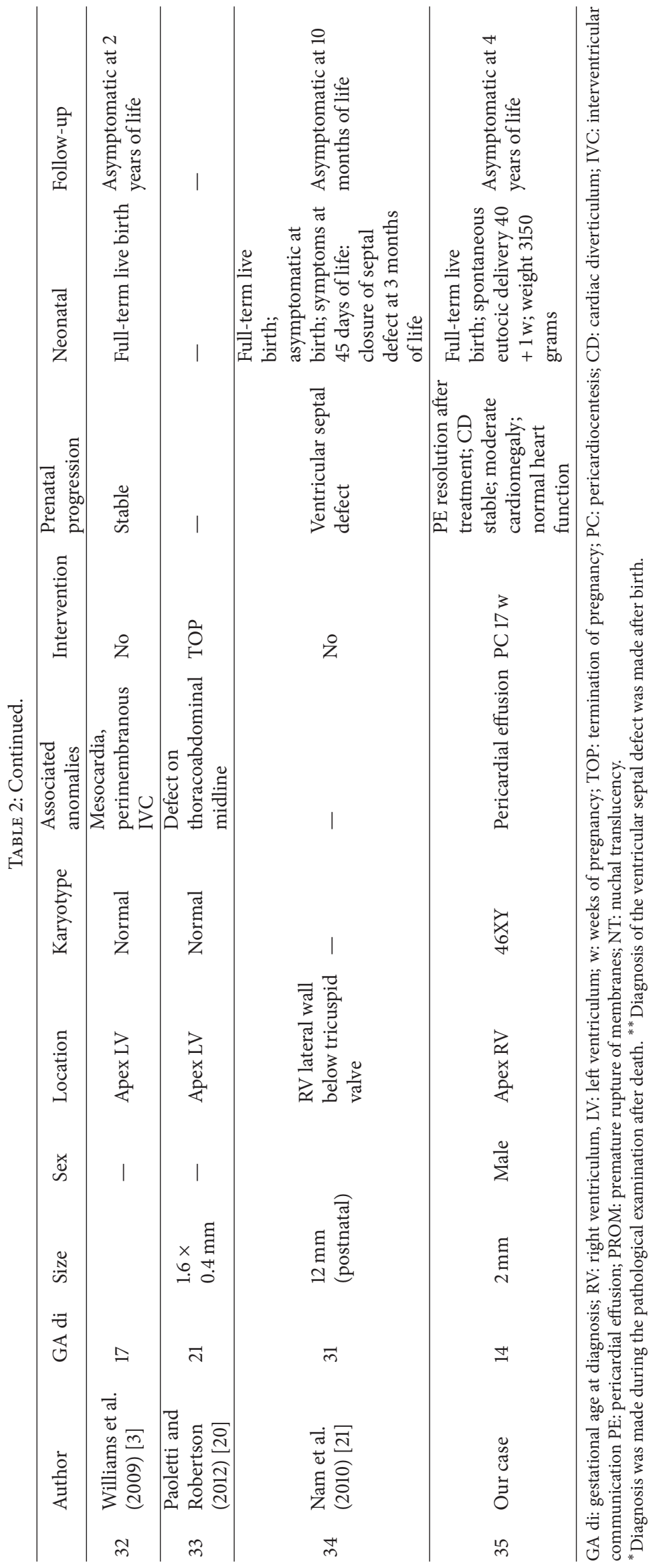




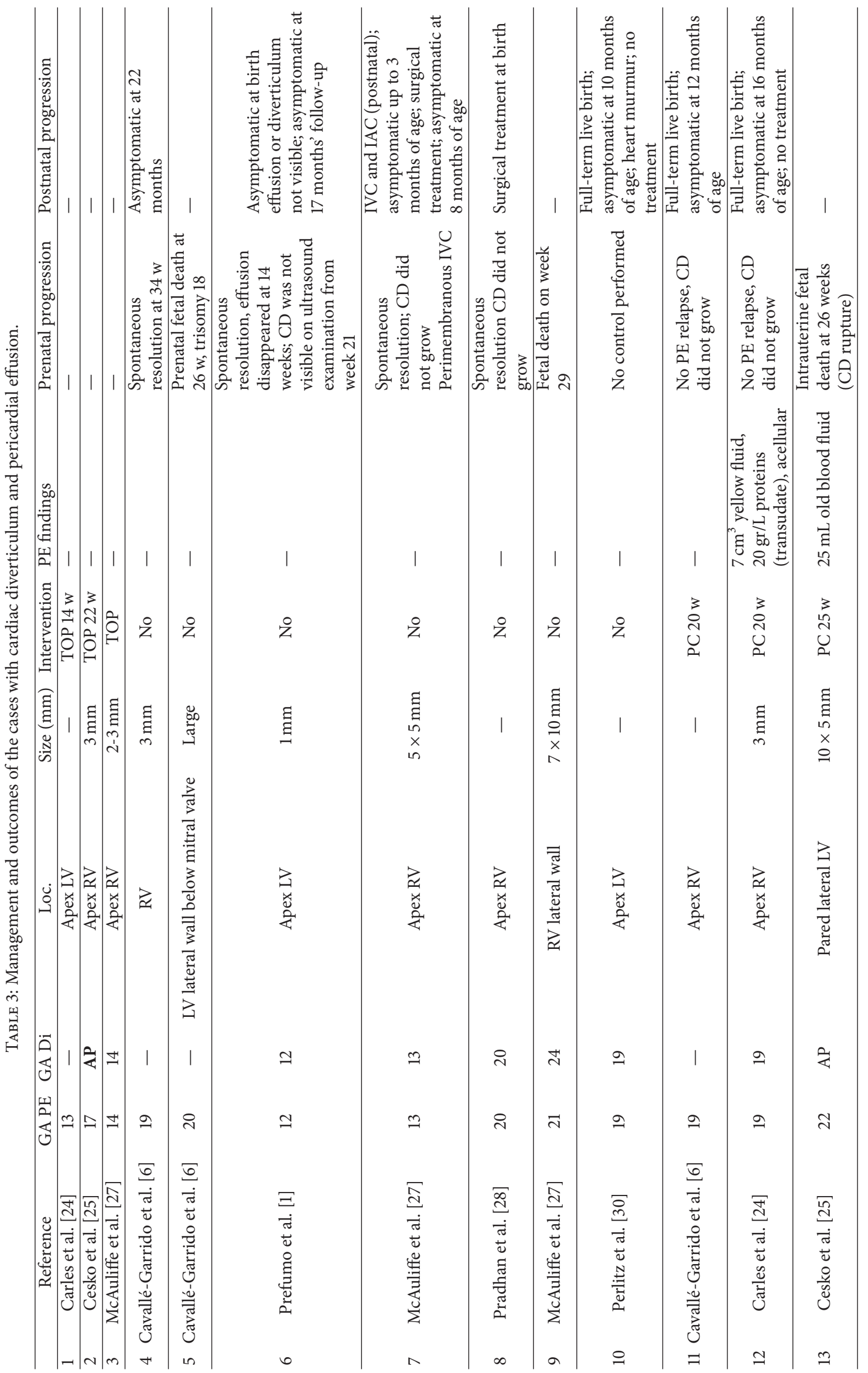




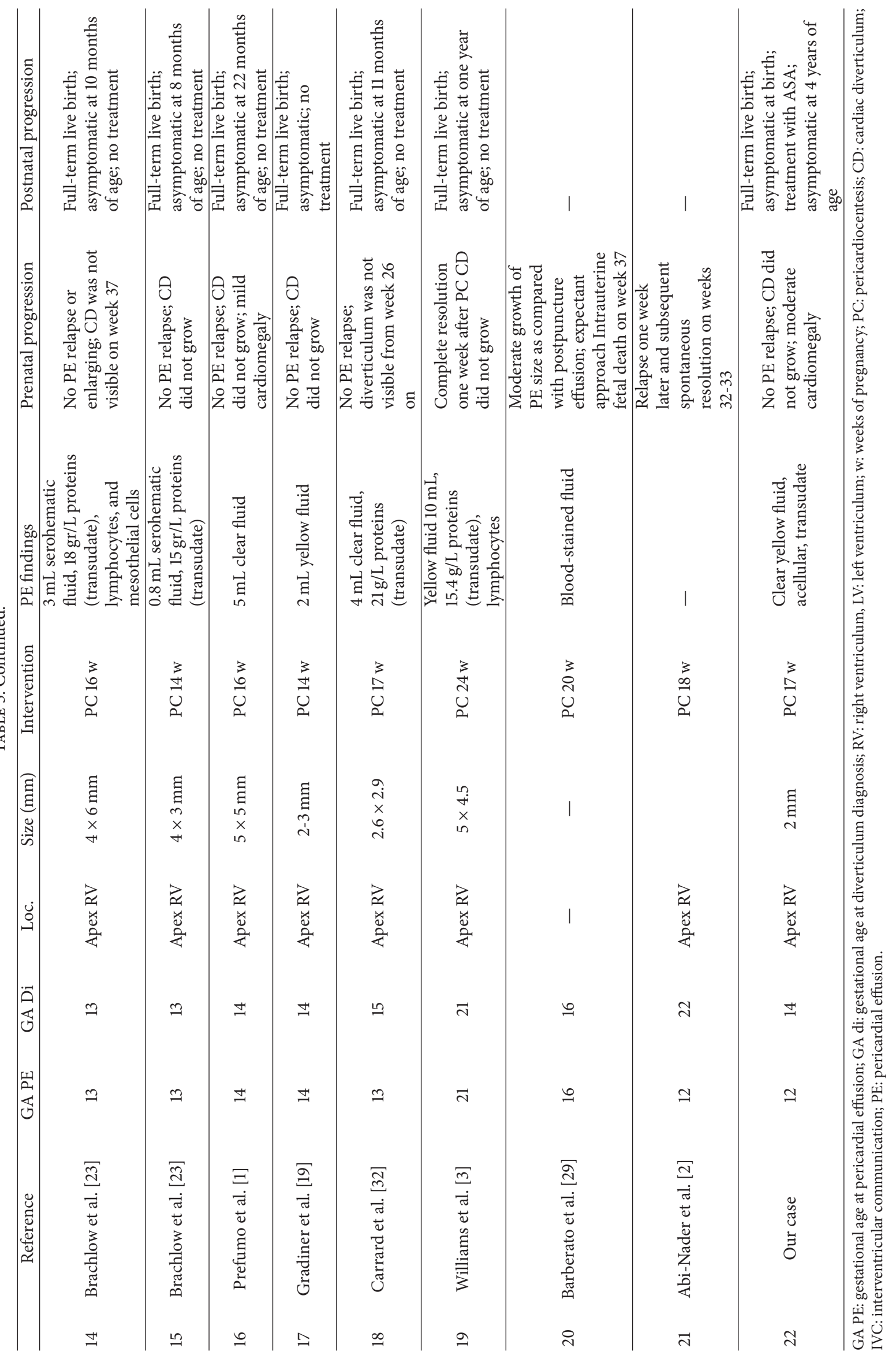


resolution (71\%) and 2 resulted in intrauterine death (29\%): one of them, which occurred on week 26 , was associated with trisomy 18 and the other, which occurred on week 29, was associated with treated twin-to-twin transfusion syndrome and death of one of the twins after treatment $[6,18]$.

Our review is the largest series published in the literature with 34 cases of fetal cardiac diverticula. If we exclude the cases of termination of pregnancy, chromosomal abnormalities, and pregnancy complications (twin-to-twin transfusion syndrome), the cardiac diverticulum is a benign condition with good postnatal outcomes, with a mortality of $0.6 \%$. In the cases with pericardial effusion, a pericardiocentesis, performed from 16 weeks of gestation with a 20 -gauge needle, seems to be a safe procedure with good outcomes in $83 \%$ of cases. The evolution of the pericardial effusion and the diverticula (spontaneous resolution, stability, or progression) is not known because there are few cases published, but the risk of cardiac insufficiency, hydrops fetalis, or pulmonary hypoplasia could be avoided with this procedure.

In our case we made an early diagnosis and treatment with pericardiocentesis with resolution of the pericardial effusion with an excellent outcome. Only 10 cases (29\%) were reported during the 11-14 weeks' scan and only 6 cases (17\%) with pericardial effusion associated during this period.

Cardiac diverticula are rarely associated with chromosomopathies especially when other malformations are not present [5]. Cardiac abnormalities usually associated with diverticula include ventricular or auricular septal defects, permeable oval foramen, tricuspid atresia, tetralogy of Fallot, persistent left superior vena cava, pulmonary artery hypoplasia, and coarctation of the aorta [5]; cardiomegaly is the most frequently associated complication in the third trimester, like in our case $[6,19]$. Usually associated extracardiac malformations include midline thoracoabdominal defects (omphalocele, ectopia cordis, Pentalogy of Cantrell, etc.) $[2,5,8,20-$ 22].

The prognosis of this entity is generally good, although the outcome largely depends on the size and location of associated anomalies. Cases of rupture, both pre- and postnatal, arrhythmia, fetal death, heart failure, and coronary insufficiency have been described $[9,16,18,21,23]$. In these patients, serial control examinations are necessary to detect possible complications. In general, postnatal progression is good and surgery is not necessary in asymptomatic cases [19].

In conclusion, a cardiac diverticulum is a rare entity. The most frequently associated complication is pericardial effusion, which may result in cardiac decompensation, hydrops fetalis, or pulmonary hypoplasia. Although spontaneous resolution of effusion has been reported, pericardiocentesis is a safe and effective technique, which may be used to reduce the risk of secondary disorders in selected cases. Nowadays there are few cases published and the evidence is poor to establish the appropriated management.

\section{Conflict of Interests}

The authors declare no conflict of interests.

\section{References}

[1] F. Prefumo, A. Bhide, B. Thilaganathan, and J. S. Carvalho, "Fetal congenital cardiac diverticulum with pericardial effusion: two cases with different presentations in the first trimester of pregnancy," Ultrasound in Obstetrics \& Gynecology, vol. 25, no. 4, pp. 405-408, 2005.

[2] K. Abi-Nader, A. L. David, R. Yates, and P. Pandya, "Successful outcome after prenatal treatment of a cardiac diverticulum with massive pericardial effusion," Fetal Diagnosis and Therapy, vol. 25, no. 1, pp. 148-152, 2009.

[3] J. A. Williams, K. R. Collardey, M. C. Treadwell, and S. T. Owens, "Prenatally diagnosed right ventricular outpouchings: a case series and review of the literature," Pediatric Cardiology, vol. 30, no. 6, pp. 840-845, 2009.

[4] H. A. Baltaxe, W. J. Wilson, and M. Amiel, "Diverticulosis of the left ventricle," American Journal of Roentgenology, vol. 133, no. 2, pp. 257-261, 1979.

[5] M. A. Ohlow, B. Lauer, M. Brunelli, and J. C. Geller, "Ventricular aneurysms are different from ventricular diverticula," Circulation Journal, vol. 77, no. 1, p. 276, 2013.

[6] T. Cavallé-Garrido, A. Cloutier, J. Harder, C. Boutin, and J. F. Smallhorn, "Evolution of fetal ventricular aneurysms and diverticula of the heart: an echocardiographic study," American Journal of Perinatology, vol. 14, no. 7, pp. 393-400, 1997.

[7] U. Gembruch, E. Steil, D. A. Redel, and M. Hansmann, "Prenatal diagnosis of a left ventricular aneurysm," Prenatal Diagnosis, vol. 10, no. 3, pp. 203-209, 1990.

[8] B. Treistman, D. A. Cooley, R. Lufschanowski, and R. D. Leachman, "Diverticulum or aneurysm of left ventricle," The American Journal of Cardiology, vol. 32, no. 1, pp. 119-123, 1973.

[9] L. K. Hornberger, B. Dalvi, and B. R. Benacerraf, "Prenatal sonographic detection of cardiac aneurysms and diverticula," Journal of Ultrasound in Medicine, vol. 13, no. 12, pp. 967-970, 1994.

[10] P. Hallali, B. Iung, A. Davido, J.-P. Binet, H. Leriche, and P. Corone, "Congenital diverticulum of the right ventricle: report of two cases associated with other congenital heart defects," American Heart Journal, vol. 117, no. 4, pp. 957-959, 1989.

[11] T. Krasemann, J. Gehrmann, H. Fenge, V. Debus, H. Loeser, and J. Vogt, "Ventricular aneurysm or diverticulum? Clinical differential diagnosis," Pediatric Cardiology, vol. 22, no. 5, pp. 409-411, 2001.

[12] D. W. Teske, J. J. McGovern, and H. D. Allen, "Congenital fibrous left ventricular diverticulum," American Heart Journal, vol. 126, no. 5, pp. 1233-1235, 1993.

[13] D. Kitchiner, M. P. Leung, and R. Arnold, "Isolated congenital left ventricular diverticulum: echocardiographic features in a fetus," American Heart Journal, vol. 119, no. 6, pp. 1435-1437, 1990.

[14] J. R. Wax, A. Moran, M. G. Pinette, A. Reyes, A. Cartin, and J. Blackstone, "Prenatal sonographic diagnosis of fetal right ventricular diverticulum," Journal of Ultrasound in Medicine, vol. 26, no. 2, pp. 267-270, 2007.

[15] A. Davidson, V. Whiteman, and J. W. Gaynor, "Images in cardiovascular medicine. Fetal cardiac diverticulum," Circulation, vol. 113, no. 4, article e56, 2006.

[16] J.-A. M. Johnson, G. Ryan, A. Toi, and J. Smallhorn, "Prenatal diagnosis of a fetal ventricular diverticulum associated with pericardial effusion: successful outcome following pericardiocentesis," Prenatal Diagnosis, vol. 16, no. 10, pp. 954-957, 1996. 
[17] T. Koshiishi, H. Osada, A. Hata, Y. Furugen, T. Murakoshi, and N. Mitsuhashi, "Prenatal rupture of right ventricular diverticulum: a case report and review of the literature," Prenatal Diagnosis, vol. 27, no. 12, pp. 1154-1157, 2007.

[18] M. Del Río, J. M. Martínez, M. Bennasar et al., "Prenatal diagnosis of a right ventricular diverticulum complicated by pericardial effusion in the first trimester," Ultrasound in Obstetrics \& Gynecology, vol. 25, no. 4, pp. 409-411, 2005.

[19] H. M. Gardiner, R. Wimalasundera, L. Pasquini, S. Wawryk, and S. Y. Ho, "Images in cardiovascular medicine. Pericardiocentesis at 14 weeks: effective treatment of pericardial effusion complicating right ventricular diverticulum," Circulation, vol. 112, no. 9, article e120, 2005.

[20] D. Paoletti and M. Robertson, "Prenatal diagnosis of a left ventricular diverticulum," Australasian Journal of Ultrasound in Medicine, vol. 15, pp. 112-114, 2012.

[21] K. H. Nam, J. Y. Kwon, G. H. Son, N. H. Cho, Y. W. Park, and Y. H. Kim, "Prenatally diagnosed left ventricular diverticulum with thoracoabdominal wall defect: a case and review of the literature," Journal of Perinatology, vol. 30, no. 11, pp. 760-762, 2010.

[22] P. M. Olorón, C. R. Ibarra, and J. M. Galdeano Miranda, "Right ventricular outpouching associated with a ventricular septal defect: case report," Pediatric Cardiology, vol. 32, no. 8, pp. 12691270, 2011.

[23] A. Brachlow, C. Sable, S. Smith, M. Slack, and G. Martin, "Fetal diagnosis and postnatal follow-up o fan asyntomatic congenital Leith ventricular diverticulum," Pediatric Cardiolog, vol. 23, no. 6, pp. 658-660, 2006.

[24] D. Carles, B. Maugey-Laulom, H. Habboud, E. M. Alberti, W. Weichhold, and F. Leger, "Early prenatal diagnosis of ventricular diverticulum complicated by serous pericardial effusion," Prenatal Diagnosis, vol. 15, no. 8, pp. 778-780, 1995.

[25] I. Cesko, J. Hajdú, Z. D. Csapó, T. Tóth, B. Sipos, and Z. Papp, "Fetal hydropericardium associated with left ventricular diverticulum," Prenatal Diagnosis, vol. 18, no. 7, pp. 721-724, 1998.

[26] A. Bernasconi, A. L. Delezoide, F. Menez, E. Vuillard, J. F. Oury, and A. Azancot, "Prenatal rupture of a left ventricular diverticulum: a case report and review of the literature," Prenatal Diagnosis, vol. 24, no. 7, pp. 504-507, 2004.

[27] F. M. McAuliffe, L. K. Hornberger, S. Winsor, D. Chitayat, K. Chong, and J.-A. Johnson, "Fetal cardiac defects and increased nuchal translucency thickness: a prospective study," American Journal of Obstetrics and Gynecology, vol. 191, no. 4, pp. 14861490, 2004.

[28] M. Pradhan, A. Dalal, A. Kapoor, S. Kumar, and R. Manisha, "Fetal left ventricular diverticulum presenting as dysrhythmia: diagnosis and management," Fetal Diagnosis and Therapy, vol. 23, no. 1, pp. 10-14, 2007.

[29] M. F. A. Barberato, S. H. Barberato, C. N. Binotto, M. J. M. Cavalcanti, A. P. Passos, and N. I. Miyague, "Prenatal diagnosis of left ventricular aneurysm and diverticulum," Arquivos Brasileiros de Cardiologia, vol. 93, no. 2, pp. e36-e38, 2009.

[30] Y. Perlitz, M. Mukary, A. Lorber, and M. Ben-Ami, "Prenatal diagnosis of fetal cardiac right ventricular diverticulum disappearing at three months of age: a case report and literature review," Fetal Diagnosis and Therapy, vol. 25, no. 1, pp. 44-46, 2009.

[31] S. Menahem, "Fetal diagnosis of a cardiac diverticulum and pericardial effusion," Fetal Diagnosis and Therapy, vol. 28, no. 1, article 46, 2010.
[32] C. Carrard, J. Massardier, N. Pangaud, and F. Champion, "Fetal right ventricular diverticulum with pericardial effusion: report of a new case treated by in utero pericardiocentesis," Pediatric Cardiology, vol. 31, no. 6, pp. 891-893, 2010. 


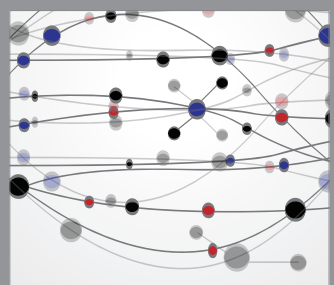

The Scientific World Journal
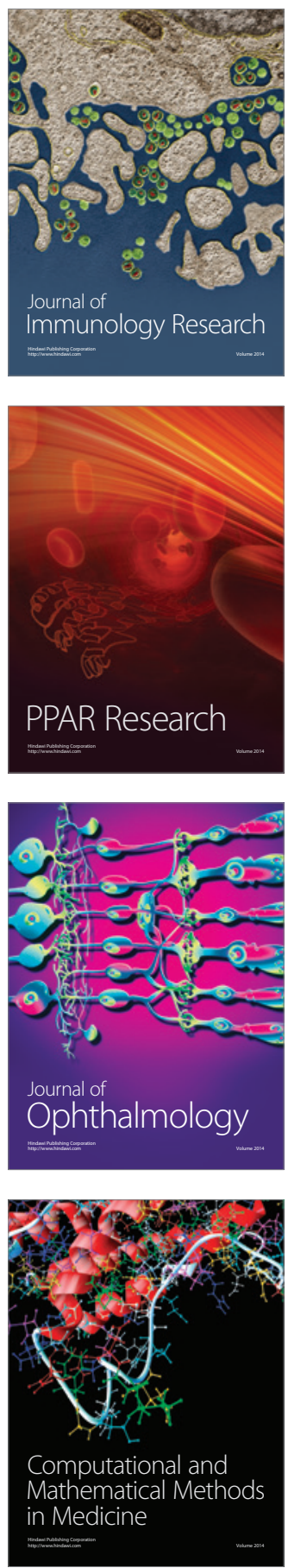

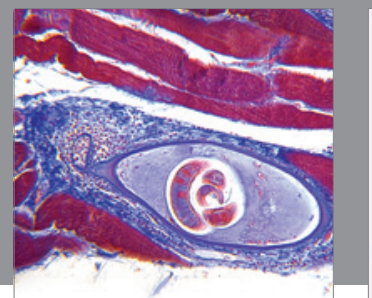

Gastroenterology

Research and Practice
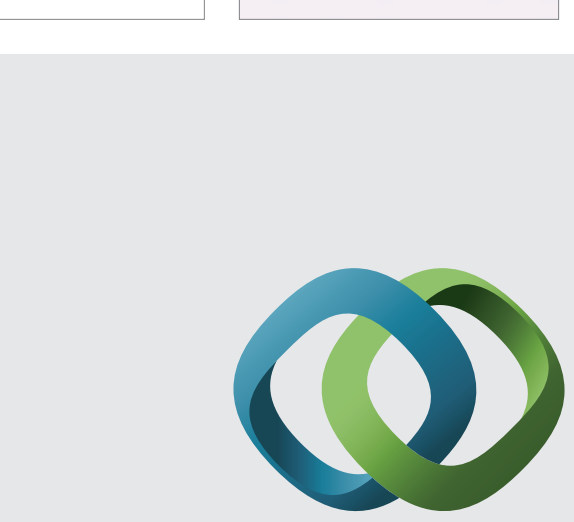

\section{Hindawi}

Submit your manuscripts at

http://www.hindawi.com
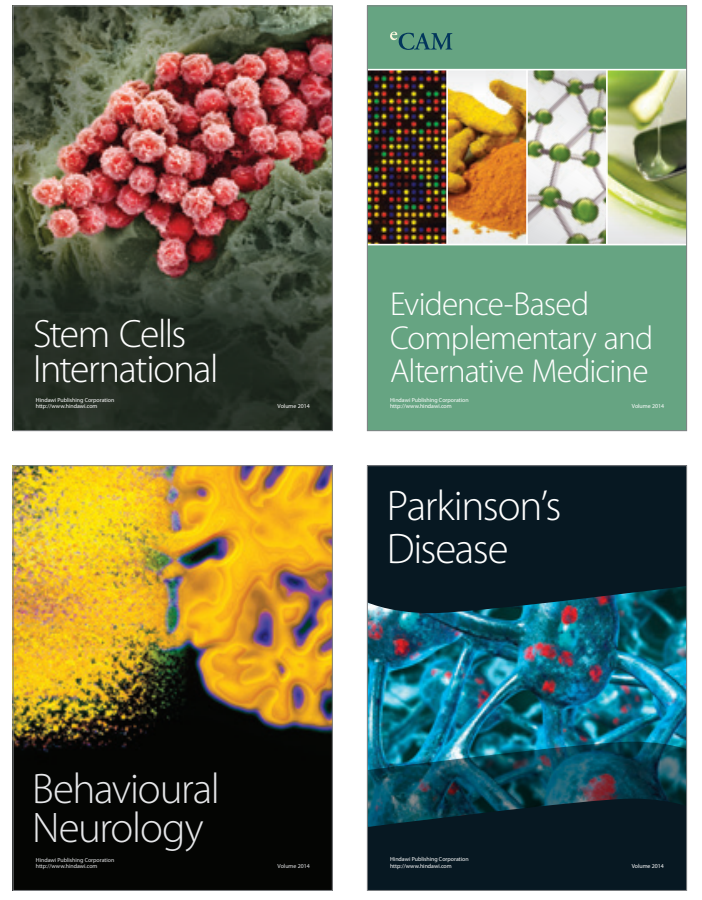
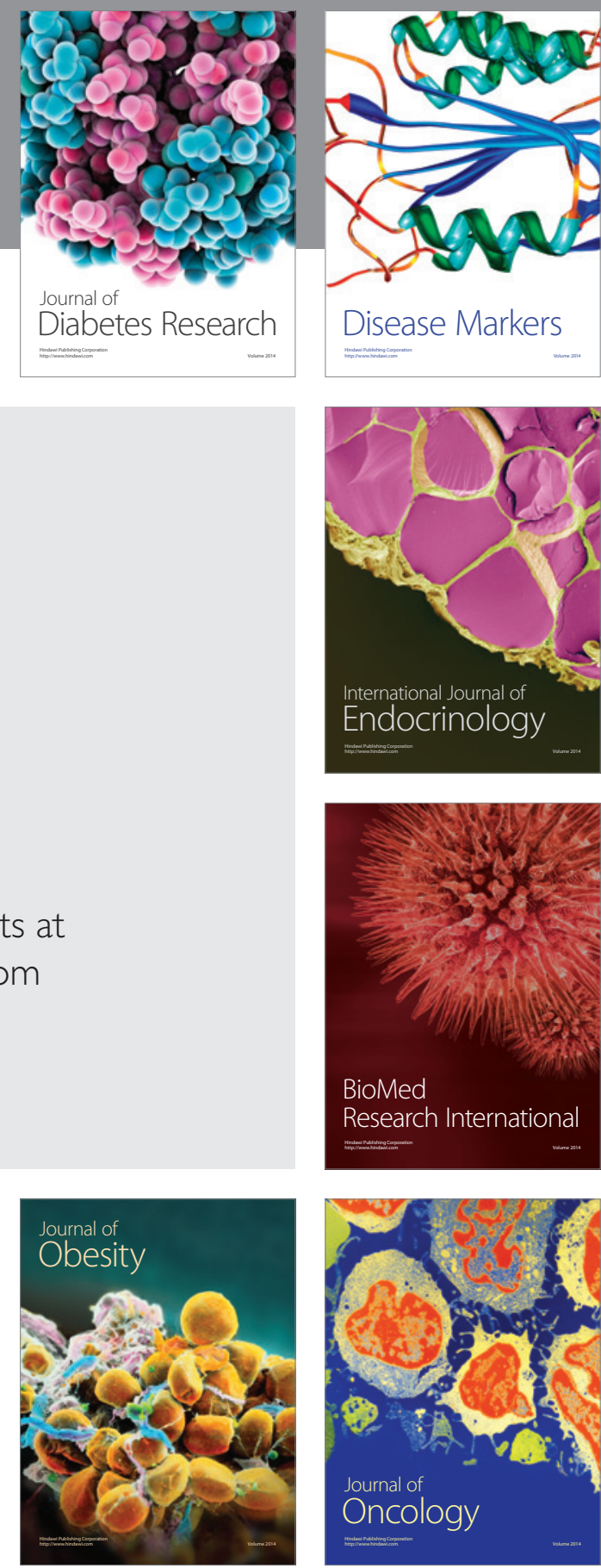

Disease Markers
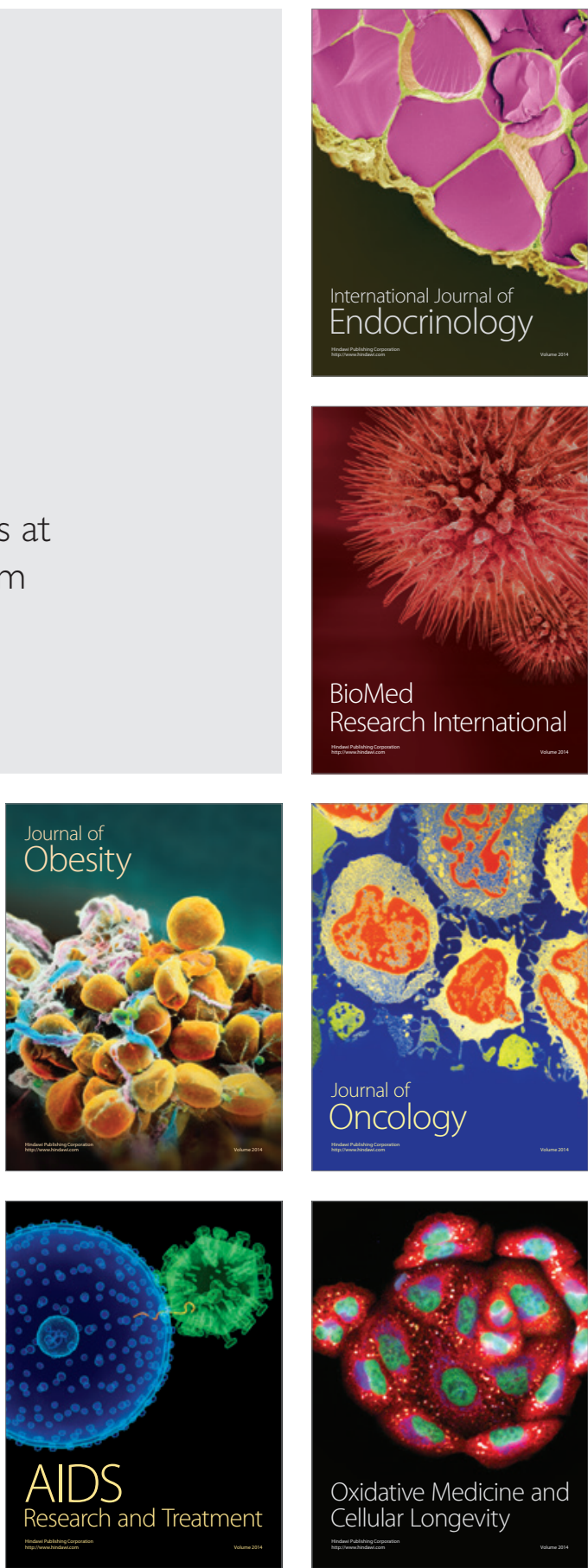